\title{
Effect of feeding regime on the performance and blood parameters of male and female broiler chickens
}

\author{
E. Tůmová1\#, D. Chodová1 ${ }^{1 \#}$ H. Härtlová ${ }^{2}$ A. Fučiková ${ }^{2}$ \& M. Ketta ${ }^{1}$ \\ ${ }^{1}$ Department of Animal Husbandry, Czech University of Life Sciences Prague, 16500 Prague Suchdol, Czech Republic \\ ${ }^{2}$ Department of Veterinary Sciences, Czech University of Life Sciences Prague, 16500 Prague Suchdol, Czech \\ Republic
}

(Received 22 August 2018; Accepted 13 December 2018; First published online 4 April 2019)

\author{
Copyright resides with the authors in terms of the Creative Commons Attribution 4.0 South African Licence. \\ See: http://creativecommons.org/licenses/by/4.0/za \\ Condition of use: The user may copy, distribute, transmit and adapt the work, but must recognise the authors and \\ the South African Journal of Animal Science.
}

\begin{abstract}
The aim of the present study was to evaluate the effect of feeding regime on changes in growth, mortality, carcass composition, and blood parameters of male and female broiler chickens during feed restriction and the realimentation period. In the experiment, males and females were split into three groups: i) ADL, a group fed ad libitum during the entire experiment; ii) R80, a group that received $80 \%$ ad libitum; and iii) R65, a group that received 65\% ad libitum. Restriction was applied in both groups from 7 to 14 days old. Daily weight gain (DWG) was reduced significantly in males to $35 \%$ in R80 and 39\% in R65, and in females to $40 \%$ in R80 and $45 \%$ in R65. Insignificant compensatory growth occurred in the last week of the growing period. Feed restriction reduced mortality, with a higher mortality reduction in the R65 groups. There was no effect of feed restriction on dressing percentage or thigh yield. However, breast yield was lower and abdominal fat yield was higher in restricted birds. There was a minor effect of feeding regime on blood biochemical and haematological measurements. Males showed significantly higher compensatory growth, feed intake, mortality and thigh yield than females, but dressing percentage and abdominal fat levels were significantly higher in females. Blood total protein and urea concentration were affected by the interaction between sex, group and age.
\end{abstract}

Keywords: blood measurements, carcass yield, feed restriction, growth

\#Corresponding author: tumova@af.czu.cz

\section{Introduction}

In the past, commercial strains of broilers suffered severely from metabolic disturbances, such as ascites and sudden death syndrome (SDS), as well as from weak leg bones caused by tibial dyschondroplasia. As a result, management strategies were suggested that could prevent these problems, including the use of mashed feed, a short day length and restricted feeding programmes (Gous, 2010). The feeding regime, namely ad libitum and feed restriction, affects growth, mortality, carcass composition and physiological measurements. In broiler chickens, early feed restriction has been applied mostly in the second week of age. During the period following restriction, chickens are fed ad libitum. Early feed restriction may induce compensatory growth in the realimentation period (Govaerts et al., 2000; Tủmová et al., 2002; Van der Klein et al., 2017). Feed restriction has been shown to reduce the high mortality generally observed in commercial broiler operations (Tůmová et al., 2002). Lower mortality of restricted chickens is due to a decreased incidence of SDS and ascites (Lippens et al., 2000; Mohammadalipour et al., 2017) and leg problems (Lippens et al., 2000). Carcass composition may be negatively affected by feed restriction (Lippens et al., 2000; Zhan et al., 2007). However, Van der Klein et al. (2017) did not find such an effect of feed restriction on carcass composition.

Blood measurements give information about animal health and metabolism, though Zhan et al. (2007) and Mohammadalipour et al. (2017) did not find effects of feed restriction on blood biochemical parameters. Effects of feed restriction on performance, carcass composition and physiological conditions are affected by the commencement, intensity and duration of feed restriction. Similarly, the parameters may differ in males and females. Therefore, the aim of the present study was to evaluate the effect of a feeding regime on 
changes in growth, mortality, carcass composition and blood parameters of male and female broiler chickens during feed restriction and realimentation.

\section{Materials and Methods}

The growth study with 2340 Ross 308 chickens was carried out from one day to five weeks old at the International Poultry Testing Station Ústrašice, and was approved by the Ethics Committee of the Central Commission for Animal Welfare at the Ministry of Agriculture of the Czech Republic. On the first day of the experiment, chickens were wing-banded and placed in 18 littered pens. A total of 135 chickens were housed in each pen, with a floor density of $16 \mathrm{birds} / \mathrm{m}^{2}$. The experiment consisted of six treatments according to feeding regime and sex $(3 \times 2 \times 135)$. The ADL groups, males and females, were fed ad libitum for the entire experiment. Food intake of the R80 group (males and females) was restricted from 7 to 14 days old, during which time they received $80 \%$ of ad libitum intake. Similarly, the R65 group (males and females) received $65 \%$ of the ad libitum intake during the same seven-day period. Chickens in the restricted groups were fed ad libitum before and after the restriction period. Chickens of all groups received commercial feed mixtures, including a starter to 14 days $(23.4 \%$ crude protein $(\mathrm{CP}), 6.4 \%$ ether extract (EE), $12.7 \mathrm{MJ}$ metabolizable energy, ME), a grower to 28 days (20.9\% CP, $8.0 \% \mathrm{EE}, 12.7 \mathrm{MJ} \mathrm{ME})$, and a finisher to 35 days (20.0\% CP, 8.3\% EE, 13.2 MJ ME). Environmental conditions were maintained according to the chickens' requirements, and a 19-hour photoperiod was used.

The growth of the chickens was evaluated by calculating the daily weight gain (DWG) from weekly individual weighing. Average daily feed intake (FI) was measured weekly for each pen. The mortality of chickens was recorded daily with detection of SDS. During the experiment, at the ages of 2, 3, 4 and 5 weeks, four chickens with average pen weight were selected from each pen (total of 12 chickens per group) for sampling. After slaughtering, defeathering and evisceration, carcasses were cooled overnight at $4{ }^{\circ} \mathrm{C}$. Internal organs, heart and liver were weighed after evisceration. The second day after slaughtering, the cold carcasses were dissected, with breast, thigh and abdominal fat being separated. The weights of the carcass, carcass parts and organs were used to calculate the dressing percentage and parts yielded from the carcass.

Blood samples for the biochemical parameters were collected from a jugular vein from each slaughtered bird at each slaughtering time. Serum was separated by centrifugation and stored at $-70{ }^{\circ} \mathrm{C}$ until analyses were conducted. Total protein (TP), albumin (ALB), urea (UA), triacylglycerol (TAG), total cholesterol $(\mathrm{CHOL})$ and glucose (GLU) concentrations were determined with the Randox commercial set (Randox Laboratories Ltd., Crumlin, UK) on a Libra S22 spectrophotometer (Biochrom Ltd., Cambourne, Cambridge, UK). The blood picture was analysed at the age of 2 and 5 weeks only in groups of males. Haematology characteristics, erythrocyte (ER) number, leucocyte (LE) number, lymphocyte (LY) number, neutrophil (NE) number, haemoglobin (HB) and haematocrit value $(\mathrm{HC})$ were analysed in the samples, which were stabilized with $\mathrm{K}_{2}$ EDTA using a Coulter Model ZF (Coulter Electronics Ltd., Luton, Beds, UK). ER number and $\mathrm{HC}$ were used to calculate the mean cell volume (MCV).

The results of the experiment were evaluated with a GLM procedure of the analysis of variance (ANOVA) method using SAS (SAS Institute Inc., 2013). The DWG and average FI were analysed by two-way ANOVA with interaction of group and sex. Carcass characteristics and blood biochemical parameters were evaluated using a three-way ANOVA and interaction of group, sex and age. Blood picture was calculated using a two-way ANOVA with interaction of group and age. Variability among groups was expressed by the root mean square error (RMSE). Statistically significant differences $(P<0.05)$ are indicated by different superscripts.

\section{Results}

Growth of the chickens, expressed by DWG (Table 1$)$, was higher $(P \leq 0.001)$ in males than in females from one week old to the end of the fattening period. In the second week of the experiment, when feed restriction was applied, DWG was significantly lower in the restricted groups. Compared with the ADL chickens, males of the R80 and R65 groups decreased their DWG approximately to 35\% and 39\%, respectively, and in females in R80 and R65 to $40 \%$ and $45 \%$, respectively. In the first week after the restriction period, the restricted groups showed a higher growth rate of between $1 \%$ and $3 \%$, compared with the ADL group. This difference was even higher in the final week of the study (males: $17 \%$ in R80 and $13 \%$ in R65, females: $5.6 \%$ in R80 and 6.3\% in R65). However, these differences were not statistically significant.

As expected, $\mathrm{FI}$ (Table 2) was significantly higher in males than in females throughout the experiment. Feeding regime affected $\mathrm{FI}$ only during the restriction period $(P \leq 0.001)$ when it was reduced in the restricted groups, depending on the given amount of feed (80\% and $65 \%$ ADL). A significant interaction of sex and feeding regime $(P \leq 0.001)$ at this age showed that ADL females consumed less feed than males. Mortality (Table 3) over the five-week period decreased in the restricted groups: in males by $30 \%$ for R80 and $45 \%$ for 
R65; and in females by $23 \%$ in R80 and $70 \%$ in R65. The lower mortality was associated with a lower incidence of SDS, which was the main cause of mortality in this trial.

Table 1 Effects of sex and feeding regime on daily weight gain (g)

\begin{tabular}{|c|c|c|c|c|c|c|}
\hline Sex & Group & 0-7 days & 8-14 days & 15-21 days & 22-28 days & 29-35 days \\
\hline & ADL & 20.2 & 62.3 & 65.5 & 87.9 & 74.3 \\
\hline \multirow[t]{3}{*}{ Male } & $\mathrm{R} 80$ & 18.7 & 40.3 & 67.7 & 83.3 & 87.1 \\
\hline & R65 & 19.9 & 37.7 & 66.0 & 81.5 & 83.7 \\
\hline & ADL & 17.1 & 45.1 & 59.5 & 70.9 & 80.6 \\
\hline \multirow[t]{2}{*}{ Female } & R80 & 17.1 & 27.3 & 61.1 & 68.3 & 85.1 \\
\hline & R65 & 17.5 & 25.1 & 60.5 & 67.8 & 85.7 \\
\hline RMSE & & 0.97 & 2.58 & 3.29 & 4.11 & 13.1 \\
\hline Sex & & 0.001 & 0.001 & 0.001 & 0.001 & NS \\
\hline Group & & NS & 0.001 & NS & NS & NS \\
\hline Sex x group & & NS & NS & NS & NS & NS \\
\hline
\end{tabular}

RMSE: root mean square error

NS: not significant

ADL: ad libitum

Table 2 Effect of sex and feeding regime on average feed intake (g)

\begin{tabular}{|c|c|c|c|c|c|c|}
\hline Sex & Group & 0-7 days & 8-14 days & 15-21 days & 22-28 days & 29-35 days \\
\hline & ADL & 24.8 & $62.6^{\mathrm{a}}$ & 100.1 & 160.3 & 192.1 \\
\hline \multirow[t]{3}{*}{ Male } & $\mathrm{R} 80$ & 23.9 & $50.7^{b}$ & 96.1 & 150.2 & 196.5 \\
\hline & R65 & 23.2 & $40.1^{c}$ & 96.6 & 148.3 & 191.3 \\
\hline & ADL & 22.1 & $54.6^{\mathrm{b}}$ & 90.7 & 132.3 & 164.0 \\
\hline \multirow[t]{2}{*}{ Female } & $\mathrm{R} 80$ & 22.4 & $43.0^{c}$ & 89.9 & 129.6 & 170.1 \\
\hline & R65 & 23.2 & $36.0^{d}$ & 90.6 & 131.4 & 171.6 \\
\hline RMSE & & 1.27 & 0.88 & 3.74 & 6.09 & 6.27 \\
\hline Sex & & 0.05 & 0.001 & 0.05 & 0.001 & 0.001 \\
\hline Group & & NS & 0.001 & NS & NS & NS \\
\hline Sex x Group & & NS & 0.001 & NS & NS & NS \\
\hline
\end{tabular}

${ }^{a, b, c, d}$ Means in the same column with unlike superscripts differ $P<0.05$

RMSE: root mean square error

NS: not significant

ADL: ad libitum

Carcass composition results are given in Table 4. Dressing percentage was lower in males $(P \leq 0.05)$ and increased with age $(P \leq 0.001)$, but no effect of feeding regime was observed. On the other hand, feed restriction decreased breast yield $(P \leq 0.001)$, but did not affect thigh yield significantly. Both breast and thigh yield increased with age $(P \leq 0.001)$. Abdominal fat was higher in females $(P \leq 0.05)$ and in restricted groups $(P 0.001)$ and increased with age $(P \leq 0.001)$. Heart $(P \leq 0.05)$ and liver $(P \leq 0.001)$ yield was higher in males and lower in older chickens $(P \leq 0.001)$. Feed restriction increased the heart yield $(P \leq 0.001)$ at the end of the restriction period and during realimentation. However, liver yield was not affected by feeding regime. 
Table 3 Mortality of ad libitum and restricted males and females ( $n$ )

\begin{tabular}{lccc}
\hline Sex & Group & Mortality & Mortality SDS \\
\hline \multirow{3}{*}{ Male } & ADL & 20 & 19 \\
& R80 & 14 & 12 \\
& R65 & 11 & 10 \\
\hline \multirow{3}{*}{ Female } & ADL & 13 & 12 \\
& R80 & 10 & 9 \\
& R65 & 4 & 3 \\
\hline
\end{tabular}

ADL: ad libitum

Table 4 Effects of sex and feeding regime on carcass composition (\%)

\begin{tabular}{|c|c|c|c|c|c|c|c|c|}
\hline Sex & Group & Age & $\begin{array}{c}\text { Dressing } \\
\text { percentage }\end{array}$ & $\begin{array}{c}\text { Breast yield/ } \\
\text { carcass }\end{array}$ & $\begin{array}{c}\text { Thigh yield/ } \\
\text { carcass }\end{array}$ & $\begin{array}{l}\text { Abdominal } \\
\text { fat/carcass }\end{array}$ & $\begin{array}{c}\text { Heartl } \\
\text { carcass }\end{array}$ & $\begin{array}{c}\text { Liverl } \\
\text { carcass }\end{array}$ \\
\hline \multirow{12}{*}{ Male } & \multirow{4}{*}{ ADL } & 14 & 65.6 & 19.5 & 18.5 & 0.85 & 2.19 & 6.11 \\
\hline & & 21 & 67.8 & 23.6 & 18.9 & 1.53 & 0.97 & 4.38 \\
\hline & & 28 & 69.2 & 28.5 & 19.4 & 1.56 & 0.81 & 4.08 \\
\hline & & 35 & 71.2 & 28.2 & 21.3 & 1.83 & 0.88 & 4.22 \\
\hline & \multirow{4}{*}{ R80 } & 14 & 66.6 & 20.8 & 18.6 & 1.69 & 2.19 & 5.37 \\
\hline & & 21 & 68.7 & 22.4 & 19.7 & 1.82 & 1.01 & 4.81 \\
\hline & & 28 & 67.4 & 24.7 & 21.3 & 1.66 & 0.85 & 3.85 \\
\hline & & 35 & 78.1 & 26.5 & 20.5 & 1.96 & 0.80 & 3.44 \\
\hline & \multirow{4}{*}{ R65 } & 14 & 67.4 & 19.6 & 17.9 & 1.57 & 2.25 & 5.08 \\
\hline & & 21 & 66.1 & 20.9 & 19.5 & 2.04 & 1.08 & 5.03 \\
\hline & & 28 & 67.3 & 25.5 & 20.8 & 1.70 & 0.91 & 4.03 \\
\hline & & 35 & 72.3 & 25.3 & 21.4 & 2.02 & 0.89 & 4.24 \\
\hline \multirow{12}{*}{ Female } & \multirow{4}{*}{ ADL } & 14 & 66.3 & 22.4 & 16.8 & 1.45 & 2.01 & 4.61 \\
\hline & & 21 & 68.6 & 23.9 & 18.9 & 1.25 & 1.02 & 4.75 \\
\hline & & 28 & 71.1 & 27.9 & 19.5 & 1.81 & 0.84 & 3.81 \\
\hline & & 35 & 73.2 & 26.4 & 20.3 & 2.19 & 0.76 & 3.20 \\
\hline & \multirow{4}{*}{ R80 } & 14 & 66.9 & 20.8 & 16.8 & 1.68 & 2.01 & 4.34 \\
\hline & & 21 & 69.8 & 21.3 & 18.8 & 1.81 & 1.02 & 4.98 \\
\hline & & 28 & 70.7 & 26.7 & 19.8 & 1.85 & 0.75 & 3.82 \\
\hline & & 35 & 76.6 & 24.7 & 19.1 & 2.13 & 0.67 & 2.87 \\
\hline & \multirow{4}{*}{ R65 } & 14 & 67.4 & 18.7 & 16.8 & 1.63 & 2.08 & 4.21 \\
\hline & & 21 & 70.3 & 21.7 & 19.5 & 2.42 & 1.27 & 4.83 \\
\hline & & 28 & 70.9 & 25.9 & 20.2 & 2.47 & 0.84 & 3.65 \\
\hline & & 35 & 74.1 & 25.9 & 20.7 & 2.30 & 0.84 & 3.61 \\
\hline \multicolumn{3}{|l|}{ RMSE } & 5.19 & 2.36 & 1.81 & 0.71 & 0.19 & 0.78 \\
\hline \multicolumn{3}{|l|}{ Sex } & 0.05 & NS & 0.001 & 0.05 & 0.05 & 0.001 \\
\hline \multicolumn{3}{|l|}{ Group } & NS & 0.001 & NS & 0.001 & 0.001 & NS \\
\hline \multicolumn{3}{|l|}{ Age } & 0.001 & 0.001 & 0.001 & 0.001 & 0.001 & 0.001 \\
\hline \multicolumn{3}{|c|}{ Sex x Group x Age } & NS & NS & NS & NS & NS & NS \\
\hline
\end{tabular}

RMSE: root mean square error; NS: not significant

ADL: ad libitum 
Blood biochemical parameters give information about the metabolism in chickens. All parameters were within physiological range. However, the factors that were evaluated affected some of the parameters. TP concentration was influenced by the interaction of sex, feeding regime and age $(P \leq 0.05)$. The highest TP concentration was in ADL males at 5 weeks, and the lowest was in R80 females at 4 weeks. TP increased with age $(P \leq 0.001)$ and was higher in males $(P \leq 0.001)$. Similar trends were observed in the concentration of uric acid, which was also lower in the restricted groups $(P \leq 0.001)$. The third parameter of the protein metabolism, ALB, increased only with advancing age $(P \leq 0.001)$. Both parameters of lipid metabolism, TAG and $\mathrm{CHOL}$, were significantly higher in males and older birds. On the other hand, females had lower glucose concentration $(P \leq 0.05)$, and the measurement decreased with age $(P \leq 0.001)$.

Table 5 Effects of sex and feeding regime on blood biochemical parameters

\begin{tabular}{|c|c|c|c|c|c|c|c|c|}
\hline Sex & Group & Age & TP (g/L) & $\begin{array}{l}\text { ALB } \\
(\mathrm{g} / \mathrm{L}) \\
\end{array}$ & $\begin{array}{c}\text { UA } \\
(\mathrm{mmol} / \mathrm{L})\end{array}$ & TAG (mmol/L) & CHOL (mmol/L) & GLU (mmol/L) \\
\hline \multirow{12}{*}{ Male } & \multirow{4}{*}{ ADL } & 14 & $31.5^{\mathrm{g}}$ & 14.1 & $0.51^{c}$ & 0.68 & 4.27 & 15.2 \\
\hline & & 21 & $42.6^{\mathrm{e}}$ & 19.0 & $0.41^{d}$ & 0.79 & 4.82 & 17.6 \\
\hline & & 28 & $46.2^{\mathrm{de}}$ & 10.6 & $0.37^{\mathrm{e}}$ & 1.38 & 3.88 & 17.7 \\
\hline & & 35 & $62.3^{\mathrm{a}}$ & 25.8 & $0.77^{\mathrm{a}}$ & 1.80 & 4.83 & 13.6 \\
\hline & \multirow{4}{*}{ R80 } & 14 & $31.5^{9}$ & 14.4 & $0.28^{\mathrm{ef}}$ & 0.76 & 5.30 & 11.8 \\
\hline & & 21 & $48.3^{d}$ & 28.5 & $0.41^{\mathrm{d}}$ & 1.03 & 3.91 & 14.0 \\
\hline & & 28 & $39.7^{\text {ef }}$ & 15.9 & $0.34^{\mathrm{e}}$ & 1.14 & 3.08 & 16.1 \\
\hline & & 35 & $52.2^{c}$ & 17.7 & $0.64^{b}$ & 1.38 & 4.98 & 15.7 \\
\hline & \multirow{4}{*}{ R65 } & 14 & $41.5^{\mathrm{e}}$ & 15.9 & $0.33^{\mathrm{e}}$ & 0.43 & 6.31 & 15.2 \\
\hline & & 21 & $39.5^{\dagger}$ & 17.7 & $0.54^{c}$ & 0.95 & 3.80 & 14.7 \\
\hline & & 28 & $35.1^{\dagger}$ & 16.4 & $0.20^{f}$ & 0.97 & 2.90 & 16.7 \\
\hline & & 35 & $57.7^{\mathrm{b}}$ & 26.2 & $0.48^{\mathrm{cd}}$ & 1.46 & 5.06 & 13.4 \\
\hline \multirow{12}{*}{ Female } & \multirow{4}{*}{ ADL } & 14 & $39.3^{f}$ & 14.8 & $0.46^{\mathrm{d}}$ & 0.63 & 3.49 & 13.6 \\
\hline & & 21 & $39.5^{\dagger}$ & 19.6 & $0.31^{\mathrm{e}}$ & 1.16 & 4.51 & 13.4 \\
\hline & & 28 & $33.5^{9}$ & 10.3 & $0.24^{\dagger}$ & 0.68 & 2.28 & 15.6 \\
\hline & & 35 & $43.6^{\mathrm{e}}$ & 24.2 & $0.51^{\mathrm{c}}$ & 0.81 & 3.88 & 13.4 \\
\hline & \multirow{4}{*}{ R80 } & 14 & $36.1^{\dagger}$ & 15.4 & $0.31^{\mathrm{e}}$ & 0.61 & 4.89 & 14.8 \\
\hline & & 21 & $35.8^{\dagger}$ & 18.1 & $0.19^{g}$ & 1.11 & 3.11 & 15.0 \\
\hline & & 28 & $26.2^{\mathrm{h}}$ & 14.0 & $0.25^{\dagger}$ & 0.81 & 2.31 & 16.8 \\
\hline & & 35 & $44.8^{\mathrm{e}}$ & 27.4 & $0.52^{c}$ & 1.02 & 4.50 & 12.0 \\
\hline & \multirow{4}{*}{ R65 } & 14 & $30.4^{g}$ & 27.1 & $0.22^{\mathrm{fg}}$ & 0.71 & 4.20 & 12.9 \\
\hline & & 21 & $47.7^{\mathrm{d}}$ & 18.6 & $0.31^{\mathrm{e}}$ & 0.77 & 3.78 & 14.3 \\
\hline & & 28 & $27.1^{\mathrm{b}}$ & 10.4 & $0.19^{g}$ & 0.73 & 2.77 & 14.5 \\
\hline & & 35 & $47.3^{d}$ & 22.1 & $0.70^{\mathrm{ab}}$ & 0.76 & 3.81 & 11.4 \\
\hline \multicolumn{3}{|l|}{ RMSE } & 11.9 & 0.94 & 0.13 & 0.44 & 1.33 & 3.76 \\
\hline \multicolumn{3}{|l|}{ Sex } & 0.001 & NS & 0.001 & 0.001 & 0.001 & 0.05 \\
\hline \multicolumn{3}{|l|}{ Group } & NS & NS & 0.001 & NS & NS & NS \\
\hline \multicolumn{3}{|l|}{ Age } & 0.001 & 0.001 & 0.001 & 0.001 & 0.001 & 0.001 \\
\hline \multicolumn{3}{|c|}{ Sex $x$ group $x$ age } & 0.05 & NS & 0.001 & NS & NS & NS \\
\hline
\end{tabular}

a,b,c,d,e,f, g,h Means in the same column with unlike superscripts differ $P<0.05$

RMSE: root mean square error

NS: not significant

ADL: ad libitum

TP-total protein; ALB-albumin; UA-urea; TAG-triacylglycerol; CHOL-cholesterol; GLU-glucose 
The blood picture was analysed only in males (Table 6) and was less affected by feeding regime than the biochemical parameters. Feed restriction increased only the LY number $(P \leq 0.05)$ compared with that of the ADL cockerels. ER, LE, MCV, HB, and HC were affected by age, with significantly higher values at the end of the experiment.

Table 6 Haematological characteristics of ad libitum and restricted males

\begin{tabular}{|c|c|c|c|c|c|c|c|c|}
\hline Group & Age & ER (T/L) & LE (G/L) & LY (\%) & NE (\%) & MCV (fL) & HB (G/dL) & $\mathrm{HC}(\mathrm{L} / \mathrm{L})$ \\
\hline \multirow{2}{*}{ ADL } & 14 & 2.98 & 4.40 & 59.4 & 30.0 & 149 & 29.4 & 44.7 \\
\hline & 35 & 3.47 & 3.86 & 61.3 & 32.8 & 145 & 25.1 & 50.3 \\
\hline \multirow{2}{*}{ R80 } & 14 & 2.87 & 3.57 & 65.6 & 25.7 & 146 & 23.3 & 41.8 \\
\hline & 35 & 3.17 & 7.00 & 64.4 & 40.0 & 140 & 25.0 & 44.6 \\
\hline \multirow{2}{*}{ R65 } & 14 & 2.88 & 5.14 & 69.1 & 35.7 & 149 & 25.1 & 42.9 \\
\hline & 35 & 3.29 & 5.43 & 62.6 & 38.6 & 144 & 26.8 & 47.5 \\
\hline \multicolumn{2}{|l|}{ RMSE } & 0.34 & 1.49 & 4.99 & 1.28 & 4.88 & 4.33 & 5.08 \\
\hline \multicolumn{2}{|l|}{ Group } & NS & NS & 0.05 & NS & NS & NS & NS \\
\hline \multicolumn{2}{|l|}{ Age } & 0.001 & 0.001 & NS & NS & 0.001 & NS & 0.05 \\
\hline \multicolumn{2}{|c|}{ Group x age } & NS & NS & NS & NS & NS & NS & NS \\
\hline
\end{tabular}

RMSE: root mean square error

NS: not significant

ADL: ad libitum

ER-erythrocyte number; LE-leucocyte number; LY-lymphocyte number; NE-neutrophil number; MCV-mean cell volume; HB-haemoglobin, HC-haematocrit value

\section{Discussion}

Feed restriction has been widely used in broiler chickens, but finding a suitable method is not easy because variable methods of restriction give different results. Generally, after growth reduction caused by limited feeding, compensatory growth is expected. In the present study, during the restriction period, growth of males and females was more depressed than the reduction in $\mathrm{Fl}$, and the authors assume that both restricted groups consumed an amount of feed that was lower than the requirements of chickens. Significant growth reduction in the restriction period was followed by negligible compensatory growth in the first week of realimentation. There were no differences in growth between the restricted chickens and ADL chickens in the realimentation period. However, compensatory growth occurred in the last week of the experiment, corresponding with the results of Lippens et al. (2000), who found that compensatory growth does not occur until the last days of the trial or does not occur in the realimentation period. In contrast, Van der Klein et al. (2017) observed that $80 \%$ or $90 \%$ ad libitum feeding during the second week of age was not sufficiently severe for significant growth depression. Feeding $80 \%$ or $70 \%$ ad libitum induced significantly higher DWG in the first week after restriction, which was followed by a similar DWG for all groups in the next two weeks of the experiment. With regard to sex, males showed significantly higher DWG than females, but there was not a significant interaction between group and sex, which was also observed by Van der Klein et al. (2017). The lack of compensatory growth in the present study is assumed to be associated with a lower Fl during realimentation. Feed restriction improves feed utilization (Plavnik \& Hurwitz, 1988), but it appears that chickens must induce full compensatory growth by obtaining more nutrients, not only from better utilization, but also from a higher FI. Similar FI by the ADL and restricted chickens showed that restricted chickens required a longer growing period to recover the growth reduction caused by feed restriction.

Feed restriction reduced the mortality of chickens, which agrees with the findings of Lippens et al. (2000). A more severe feed restriction had a higher impact on decreasing the mortality. The lower mortality of restricted chickens was associated with a lower rate of death of chickens caused by SDS. SDS is a major non-infectious cause of death in broiler chickens, which affects mostly males (Gesek et al., 2016), which was observed in the present study. SDS is considered a cardiac disease (Scorza et al., 2009), and the incidence of SDS in chickens is associated with pathological changes in the heart (Olkowski et al., 2008; Gesek et al., 2016). However, feed restriction in males and females significantly increased the heart yield compared with that in ADL chickens, and the trend continued during realimentation. Similar results have been observed in 
rabbits (Tůmová et al., 2007) and lambs (Santos et al., 2018). A larger heart size in restricted animals may lead to myocyte hypertrophy and is assumed to be an adaptive response (Santos et al., 2018). Mohammadalipour et al. (2017) stated that the growing heart mass elevated HC to satisfy the oxygen demand of the increased metabolic rate. However, in the present study, HC was lower numerically in restricted males and might be associated with the lack of compensatory growth. Regarding sex, the results of mortality and heart yield were significantly higher in males.

The feeding regime did not have an effect on dressing percentage. However, the measurement was significantly higher in females and increased with age. Variable results of the effect of limited feeding on carcass composition have been described in the literature. Lippens et al. (2000) observed a lower carcass yield only in groups with the most severe restriction, whereas Saleh et al. (2005) found an increasing dressing percentage in the restricted birds. These inconsistent results might be related to the feed restriction method and conditions in the realimentation period. On the other hand, differences in dressing percentage could be affected by the development of the body parts. In the present study, restricted chickens of both sexes showed a significantly lower breast yield than that of the ADL chickens. In contrast, Saleh et al. (2005) reported improved breast yield, whereas Lippens et al. (2000) and Van der Klein et al. (2017) found no effect of feeding regime on this tissue. In addition, Van der Klein et al. (2017) observed higher breast muscle growth in females, but no interaction of feeding and sex of chickens. Thigh yield was not affected by feeding regime, which agrees with the results of Lippens et al. (2000) and Van der Klein et al. (2017), but was significantly higher in males. The effect of feed restriction on abdominal fat content is not clear, and the literature gives ambiguous results. As expected, abdominal fat increased significantly with age and grew more in females than males, which agrees with the findings of Lippens et al. (2000) and Van der Klein et al. (2017). The higher fat content observed in females, according to De Souza Khatlab et al. (2018), is associated with a higher FAS gene expression in females, which is related to lipid synthesis. Abdominal fat was increased significantly in the restricted chickens than in the ADL chickens, and showed no effect from the intensity of feed restriction. Lippens et al. (2000) found no significantly higher abdominal fat content in restricted chickens either. Zhan et al. (2007) reported significantly higher abdominal fat content. However, Van der Klein et al. (2017) observed numerically lower abdominal fat in restricted chickens, which was not affected by the intensity of the restriction, and the allometric coefficient was markedly lower in restricted groups. These results show that the effect of feed restriction on abdominal fat, and presumably other carcass fats, are affected by many factors. In the variability of fat content, liver may play an important role, because the liver is an organ that develops early (Tưmová et al., 2016), and changes in size may reflect fat metabolism. In the present study, liver percentage was numerically higher in restricted chickens and significantly higher in males. A higher liver percentage is assumed to be a response to an increase in functional activity, such as steatosis (Makovický et al., 2012), glycogen storage (Knudsen et al., 2014), and inhibition of $\beta$-oxidation and mitochondrial activity leading to fat deposition (Santos et al., 2018). Liver lipogenesis is reflected in blood lipid metabolites. Wang et al. (2017) suggested that reduced TAG and cholesterol concentrations in blood intervenes with the reabsorption of lipids and cholesterol by absorbing bile acid and consequently disturbs lipid metabolism. However, TAG and cholesterol were numerically higher in restricted chickens in the present study, which led to a higher fat accumulation.

Blood biochemical parameters increased significantly with age and were affected by the sex of the chickens. These changes are assumed to reflect physiological changes in their metabolism. The significantly higher concentration of TAG, cholesterol and glucose in females might be related to higher fat accumulation. Feeding regime did not affect ALB, TAG, CHOL or GLU concentration. However, in TP and UA concentration, the effect of an interaction of sex, group and age was observed. Both parameters are involved in protein metabolism, and a lower concentration mainly in restricted females might be affected by a lower liver protein synthesis, which decreases plasma protein concentration (Rajman et al., 2006). Maliwan et al. (2017) suggested that urea concentration corresponds with growth performance, and in the present study, DWG was higher in the ADL groups. A short feed restriction period has a minor effect on the blood picture, with only the LY number being higher in the restricted cockerels, which agrees with the authors' results with rabbits (Tủmová et al., 2007; Chodová et al., 2017). However, a major effect on the blood picture was associated with age, where ER number, MCV, and HC increased significantly with advancing age whereas LE number decreased.

\section{Conclusion}

Based on the results, the feed restriction regimes impaired the growth of males and females, also in the realimentation period. There were negligible differences between an $80 \%$ restriction of ad libitum feeding and $65 \%$. Lower growth of the restricted chickens might be due to lower protein synthesis, which is indicated by the blood biochemical parameters of protein metabolism. The lack of compensatory growth was related to the low feed intake following the restriction period and, therefore, the lack of nutrients for induction of 
compensatory growth. There are many factors, including sex, that affect the induction of compensatory growth in early restricted broiler chickens. Higher compensatory growth was found in males. Feed restriction decreased the mortality of chickens, presumably because, during restriction, the priority of nutrients was given to the development of internal organs, which may have had a positive effect on the heart and other organs. On the other hand, higher abdominal fat in the restricted chickens, mainly females, could have been affected by the liver lipid metabolism, as indicated by the physiological measurements. The results show that the effect of feed restriction on broiler chickens is influenced by individual factors and their interactions. To reveal the involvement of these individual factors, more research is necessary.

\section{Acknowledgements} QJ1510192).

The present study was supported by the Ministry of Agriculture of the Czech Republic (Project NAAR No.

\section{Authors' Contributions}

$\mathrm{DCH}$ conducted the experiment and carcass analysis. $\mathrm{HH}$ and $\mathrm{AF}$ contributed to the blood analyses. MK was responsible for statistical evaluation. ET designed and analysed the experiment and wrote the paper.

\section{Conflict of Interest Declaration}

There are no conflicts of interest.

\section{References}

Chodová, D., Tůmová, E., Härtlová, H., Fučíková, A., Volek, Z. \& Vlčková, J., 2017. Changes of haematological and biochemical indices with age in rabbits with ad libitum and limited feed intake. Acta Vet. Brno 86, 29-35.

De Souza Khatlab, A., del Vesco, A.P., Gasparino, E. \& Rodriguez de Oliveira Neto, A., 2018. Gender and age effects on the expression of genes related to lipid metabolism in broiler liver. Czech J. Anim. Sci. 63, 103-109.

Gesek, M., Otrocka-Domagala, I., Sokól, R., Pazdzior-Czapula, K., Lambert, B.D., Wisniewska, A.M., Zechowicz, M., Mikiewicz, M. \& Korzeniowska, P. 2016. Histopathological studies of the heart in three lines of broiler chickens. Br. Poult. Sci. 57, 219-226.

Gous, R.M., 2010. Nutritional limitations on growth and development in poultry. Livest. Sci. 130, 25-32.

Govaerts, T., Room, G., Lippens, M., De Groote, G. \& Decuypere, E., 2000. Early and temporary quantitative food restriction of broiler chickens. 2. Effects on allometric growth and growth hormone secretion. Br. Poult. Sci. 41, 355-362.

Knudsen, C., Combes, S., Briens, C., Coutelet, G., Duperray, J., Rebours, G., Salaun, J-M., Travel, A., Weissman, D. \& Gidenne, T., 2014. Increasing the digestible energy intake under a restriction strategy improves the feed conversion ratio of the growing rabbit without negatively impacting the health status. Livest. Sci. 169, 96-105.

Lippens, M., Room, G., Degroote, G. \& Decuypere, E., 2000. Early and temporary quantitative food restriction of broiler chickens. 1. Effects on performance characteristics, mortality and meat quality. Br. Poult. Sci. 41, 343-354.

Makovický, P., Tůmová, E., Rajmon, R., Bízková, Z. \& Härtlová, H., 2012. The influence of restrictive feeding of chickens on the microscopic structure of their liver. Acta Vet. Brno 81, 27-30.

Maliwan, P., Khempaka, S. \& Molee, W., 2017. Evaluation of various feeding programmes on growth performance, carcass and meat qualities of Thai indigenous crossbred chickens. S. Afr. J. Anim. Sci. 47, 16-25.

Mohammadalipour, R., Rahmani, H.R., Jahanian, R., Riasi, A., Mohammadalipour, M. \& Nili, N., 2017. Effect of early feed restriction on physiological responses, performance and ascites incidence in broiler chickens raised in normal or cold environment. Animal 11, 219-226.

Olkowski, A.A., Wojnarowicz, C., Nain, S., Ling, B., Alcorn, J.M. \& Laarveld, B., 2008. A study on pathogenesis of sudden death syndrome in broiler chickens. Res. Vet. Sci. 85, 131-140.

Plavnik, I. \& Hurwitz, S. 1988. Early feed restriction in chicks: Effect of age, duration, and sex. Poult. Sci. 67, 384-390.

Rajman, M., Juráni, M., Lamošová, D., Máčajová, M., Sedláčková, M., Koštál, L., Ježová, D. \& Výboh, P., 2006. The effects of feed restriction on plasma biochemistry in growing meat type chickens (Gallus gallus). Comp. Biochem. Physiol. 145, 363-371.

Saleh, E.A., Watkins, S E., Waldroup, A.L. \& Waldroup, P.W., 2005. Effects of early quantitative feed restriction on live performance and carcass composition of male broilers grown for further processing. J. Appl. Poult. Res. 14, 87-93.

Santos, A., Valdés, C., Giradez, F.J., Lopez, S., France, J., Frutos, J., Fernandez, M. \& Andres, S., 2018. Feed efficiency and the liver proteome of fattening lambs are modified by feed restriction during the suckling period. Animal 12 , 1-9.

SAS Institute Inc., 2013. SAS System for Windows. Release 9.4.

Scorza, F.A., de Albuquerque, R., Arida, R.M., Schmidt, B., de Almeida, A.G., Scorza, C.A. \& Cavalheiro, E.A., 2009. Could sudden death syndrome (SDS) in chickens (Gallus gallus) be a valid animal model for sudden unexpected death in epilepsy (SUDEP)? Med. Hyp. 73, 67-69.

Tůmová, E., Skřivan, M., Skřivanová, V. \& Kacerovská, L., 2002. Effect of early feed restriction on growth in broiler chickens, turkeys and rabbits. Czech J. Anim. Sci. 10, 418-428.

Tůmová, E., Volek, Z., Chodová, D., Härtlová, H., Makovický, P., Svobodová, J., Ebeid, T.A. \& Uhlírová, L., 2016. The effect of 1-week feed restriction on performance, digestibility of nutrients and digestive system development in the growing rabbit. Animal 10, 1-9. 
Tůmová, E., Zita, L., Skřivanová, V., Fučíková, A., Skřivan, M. \& Burešová, M., 2007. Digestibility of nutrients, organ development and blood picture in restricted and ad libitum fed broiler rabbits. Arch. Geflügelkde. 71, 6-12.

Van der Klein, S.A.S., Silva, F.A., Kwakkel, R.P. \& Zuidhof, M.J., 2017. The effect of quantitative feed restriction on allometric growth in broilers. Poult. Sci. 96, 118-126.

Wang, S.P., Wang, W.J., Yang, D.S., Zhao, X.L., Luo, D.M. \& Guo, Y.B., 2017. Growth, carcass, and physiological traits of growing male China micro-duck fed various levels of dietary crude fibre. Czech J. Anim. Sci. 62, 347-356.

Zhan, X.A., Wang, M., Ren, H., Zhao, R.Q., Li, J.X. \& Tan, Z.L., 2007. Effect of early feed restriction on metabolic programming and compensatory growth in broiler chickens. Poult. Sci. 86, 654-660. 